\title{
On the Adhesion of Sediment to Footwear and the Implications for Geoconservation
}

\author{
Jack J. Matthews ${ }^{1,2}$ (D) Duncan Mcllroy ${ }^{1,3}$
}

Received: 23 January 2019 / Accepted: 20 May 2019 / Published online: 18 June 2019

(C) The Author(s) 2019

\begin{abstract}
The fossils at the Mistaken Point UNESCO World Heritage Site represent evidence of the oldest known, large, architecturally complex, life on Earth and are protected by the Government of Newfoundland and Labrador as part of an Ecological Reserve. Following concerns that foot traffic across the fossil surfaces was having a deleterious effect on the geoheritage, visitors were made to wear quilted 'Bama Sokkets' starting in 2009 - though the efficacy of this management technique has never been tested. Previous studies in the materials sciences have revealed that footwear erosion of rock surfaces is primarily caused by the action of sediment between the foot and the surface; however, these findings have not before been applied to geoconservation research. In this study, we examine the adhesion of sediment to several footwear types. Our experiments reveal that under wet conditions, the 'Bama Sokkets' perform poorly in repelling sediment, and as such their use as a geoconservation management tool is discouraged. This study recommends the use of hydrophobic footwear for walking on geoheritage rock surfaces and has led to policy change at the Mistaken Point UNESCO World Heritage Site.
\end{abstract}

Keywords Geoconservation · Ediacaran · Palaeontology $\cdot$ UNESCO World Heritage $\cdot$ Footwear abrasion

\section{Introduction}

The Mistaken Point Ecological Reserve (MPER) hosts fossils of the oldest known, large, architecturally complex life anywhere in the world (Boag et al. 2016; Pu et al. 2016). The site, situated on the southeastern coast of Newfoundland, Canada (Fig. 1), comprises a dramatic rocky coastline with over 100 hundred fossiliferous bedding planes dating from the middlelate Ediacaran Period. Fossils within MPER are preserved as positive and negative epirelief impressions on the upper

Electronic supplementary material The online version of this article (https://doi.org/10.1007/s12371-019-00380-3) contains supplementary material, which is available to authorized users.

Jack J. Matthews

jjmatthews@mun.ca

1 Department of Earth Sciences, Memorial University of Newfoundland, St. John's, NL A1B 3X5, Canada

2 Oxford University Museum of Natural History, Parks Road, Oxford OX1 3PW, UK

3 Bonne Bay Marine Station, Norris Point, NL A0K 3V0, Canada bedding surfaces of deep-marine gravity flows, often directly below volcanic ash-rich deposits.

The fossils of MPER have proven amongst the most difficult to decipher in the entire geological record but are crucial to shaping our understanding of the early evolution of large, morphologically complex organisms (Narbonne 2005; Fedonkin et al. 2007). The spectacular impressions of these soft-bodied macroorganisms are dominated by the rangeomorphs, most of which are complex frond-like organisms with self-similar branching (Narbonne 2004).

The scientific importance of the fossils around Mistaken Point was recognised by the Government of Newfoundland and Labrador in 1987, with the establishment of the Mistaken Point Ecological Reserve to encompass an 8.5-km stretch of coastline with an area of $5.7 \mathrm{~km}^{2}$. The Reserve was expanded to its current $17 \mathrm{~km}$ of coastline in 2003, to include a number of newly discovered fossil surfaces. After almost a decade of work, MPER was added to the UNESCO World Heritage List on July 17, 2016 (Liu and Matthews 2017).

Two of the best known and most extensively studied fossil horizons in Newfoundland are the 'D' and 'E' Surfaces (Benus 1988; Clapham et al. 2003; Matthews et al. 2017). Both these surfaces are best observed at the Mistaken Point promontory within MPER (Fig. 1c). The 'E' Surface preserves the fossilised 


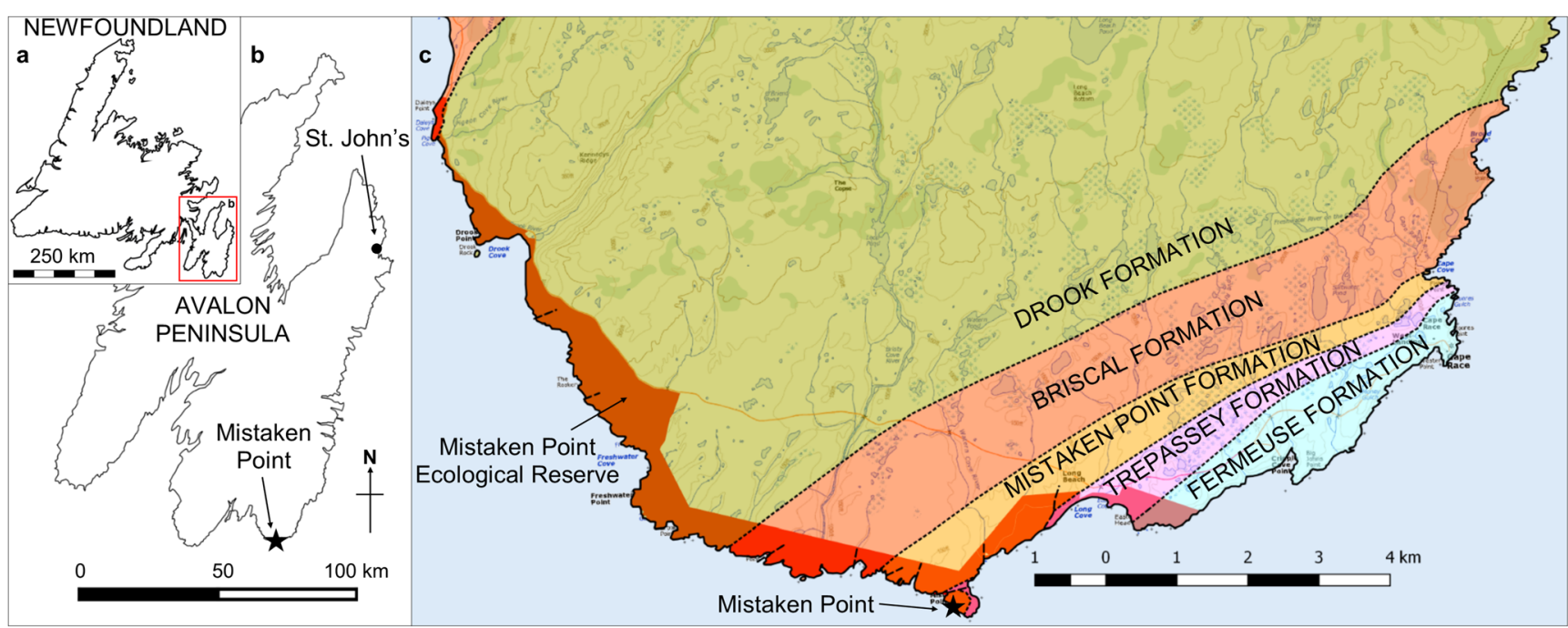

Fig. 1 Location of the Mistaken Point Ecological Reserve, Newfoundland, Canada. (a) Map of Newfoundland with Avalon Peninsula highlighted. (b) Map of the Avalon Peninsula, with MPER indicated by the star. (c) Geological map of Mistaken Point and Cape

impressions of $>4000$ organisms, some recording morphological features $<0.5 \mathrm{~mm}$ in resolution (Fig. 2). The 'E' Surface has the best preserved and most diverse assemblage in the Reserve and has been the focus of studies in palaeoecology (Clapham et al. 2003; Darroch et al. 2013, 2015; Liu et al. 2015; Mitchell et al. 2015; Dufour and Mcllroy 2017), taxonomy (Laflamme et al. 2004; Gehling and Narbonne 2007; Flude and Narbonne 2008; Bamforth and Narbonne 2009; Brasier and Antcliffe 2009; Brasier et al. 2012), and fossil preservation (Seilacher 1992; Liu et al. 2011, 2016). The volcanic ash-rich bed directly overlying the 'E' Surface has been dated to $566.25 \mathrm{Ma}$ (Pu et al. 2016)

The Mistaken Point outcrops of the 'D' and 'E' Surfaces are also the principal locality that tour groups, run by MPER staff, visit to observe the fossil horizons. Visitors
Race region, with the Mistaken Point Ecological Reserve highlighted in red. Mistaken Point itself, site of the primary outcrops of the ' $D$ ' and ' $E$ ' Surfaces, is marked by a star

must hike for $\sim 45$ min from the trailhead and, upon reaching the site, walk down off the grassed land surface and across a slope comprising glacial gravels. Before stepping onto the ' $D$ ' Surface, visitors remove their hiking footwear and put on a pair of 'Bama Sokkets', referred to locally 'bama booties'. The 'E' Surface is only accessed from the ' $D$ ' Surface. Tours operate from mid-May until mid-November (e.g. May 14-November 20 in 2016). Groups typically comprise no more than 25 visitors, with up to four MPER staff accompanying. Access to the site is only through guided tour, or with a research permit.

The wearing of 'Bama Sokkets' was brought into effect for all visitors to the ' $D$ ' and ' $E$ ' Surfaces in 2008 in response to the legitimate concern that foot traffic may be deleterious to
Fig. 2 Example of fossils on the 'E' Surface at Mistaken Point, preserved as positive and negative epirelief impressions on the upper bedding surfaces. Specimens include Beothukis mistakensis (B.m), Charniodiscus procerus (C.p), Charniodiscus spinosus (C.s), and Fractofusus misrai (F.m). Overlying horizon of volcanic ash marked. Scale bar is $10 \mathrm{~cm}$

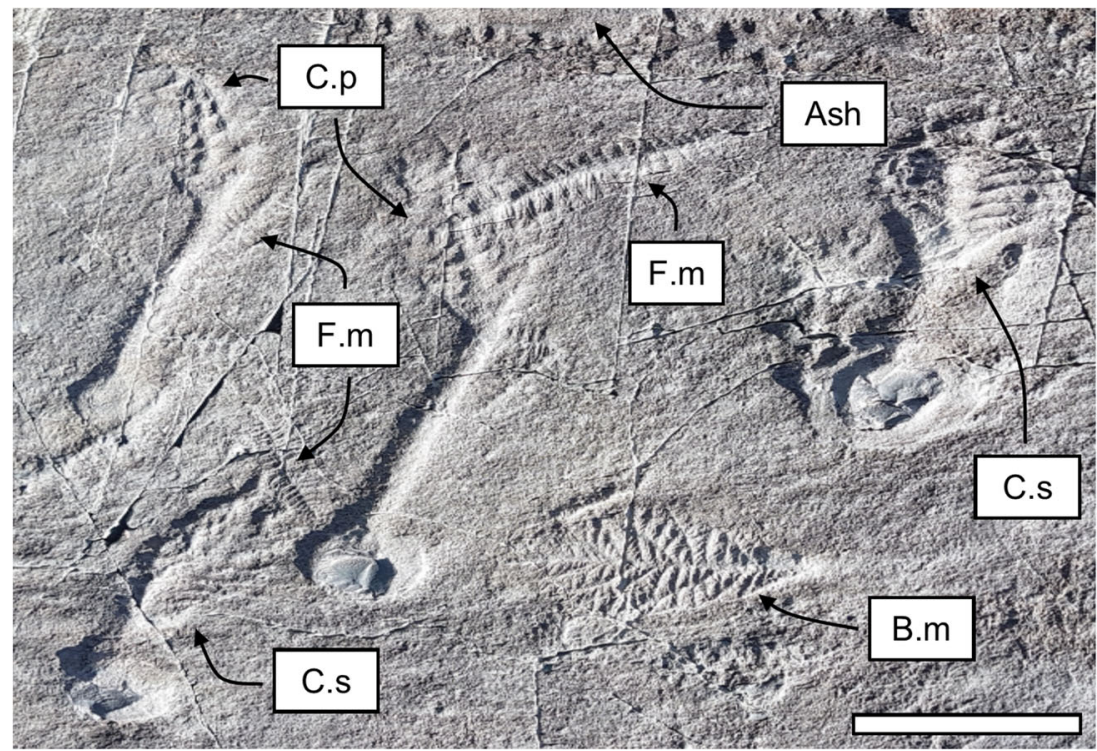


the fossils, in the belief that the soft cloth they are constructed from would prevent damage to the rock surface underfoot. This study seeks to test the efficacy of this geoconservation management technique and provide a scientific rationale for proposing the best kind of footwear from a geoconservation perspective.

\section{Method}

A sample of loose surficial sediment was collected from the area commonly used by visitors to change their footwear before stepping into the ' $\mathrm{D}$ ' Surface so as to be representative of the surface walked across in 'Bama Sokkets' before stepping onto the fossiliferous ' $D$ ' Surface. The soil sample was collected on November 4, 2016, and was damp at the time of collection. Data from the nearby Cape Race meteorological station shows the area to have received rain on every previous day since October 29, 2016. A total of $3.14 \mathrm{~kg}$ of sample was collected and transported (under permit) to the lab in sealed bag to prevent loss of moisture.

An experiment was designed to test the amount of sediment that would adhere to the base of different footwear types. This is based on the precept that the conveyance of surface sediment, an abrasive substance, on the sole of footwear would be detrimental to fossil protection. By identifying the footwear with the least sediment adhesion, we aim to determine a protocol with the best geoconservation outcomes.

In the laboratory, the damp sediment sample was transferred to a large tray and placed on the floor, next to another empty tray of known mass. The left foot of the chosen footwear type was weighed prior to testing. That footwear type would then be placed on the appropriate socked foot of the principal author. Without placing the foot on any other surface, the author then paced that foot through the tray of sediment five times (three forwards and two backwards) and then stepped that foot directly into the juxtaposed empty tray. The tested footwear was then removed, and the tray weighed to determine the mass of adherent sediment (Fig. 3). This protocol was then repeated for the right foot version of the specimen footwear. Adherent sediment was mechanically brushed off the footwear and returned to the sample tray, and the tray was mixed prior to the testing of the next footwear type. Each pair of footwear was tested three times, yielding six analyses (three left-footed and three right-footed).

Following the testing using damp sediment, the soil sample was dried in an oven at $80{ }^{\circ} \mathrm{C}$ for $24 \mathrm{~h}$. The sample was weighed and the moisture loss calculated. Testing was then repeated using the dried sediment. It is noted that some net loss of moisture could have occurred during the experiment itself, and also some mass loss of sediment may also have occurred - though every effort was made to return adhered sediment to the sample tray after each analysis.

\section{Footwear Types}

Four footwear types were chosen for testing by virtue of having been, at various times in the site's history, permissible footwear:

'Bama Sokkets' - designed as thermal insulation to be worn within shoes. They are constructed of an inner layer of polyester or acrylic fleece, with an exterior lining of cotton. These two layers are held together by stitching throughout the design. Two qualitative 'life stages' of the 'Bama Sokkets' were tested: 'nearly new bama' (Fig. 4a) that had only recently entered into use at MPER and 'old bama' (Fig. 4b, c), which constituted a pair that had been retired from use due to degradation of the cotton outer layer at the sole.

Walking socks - the design used for the experiment was the Heat Holder Men's Original. They comprise 91\% acrylic, $5 \%$ nylon, $3 \%$ polyester, and $1 \%$ elastane (Fig. 4d).

Sports socks - the design used comprised the following materials: $67 \%$ cotton, $22 \%$ polyamide, $9 \%$ polyester, and $2 \%$ elastane (Fig. $4 \mathrm{e}$ ).

Shoe - the design comprised a standard black leather shoe, with a rubber sole and boot-like tread (Fig. 4f).

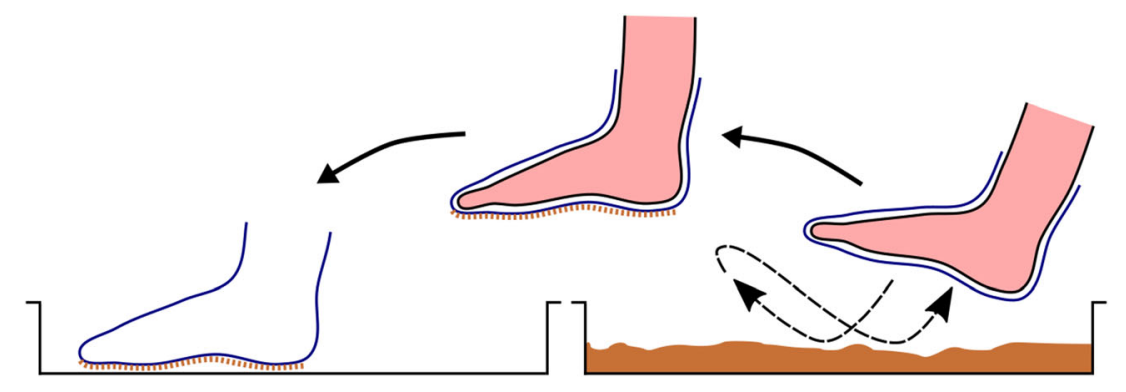

Fig. 3 Method used to test sediment adherence. Following the footwear type being fitted to the socked foot, the foot is stepped through the box of sample sediment five times. The socked foot, the affixed footwear, and

any adhered sediment is then transferred to a juxtaposed empty tray, where the socked foot is then removed, and the tray containing the footwear and sediment is weighed 
Fig. 4 Types of footwear used in the study. (a) 'Nearly new bama' and (b) 'old bama', sole upwards. (c) Old bama following testing, zoomed into the ball of foot area. (d) Walking socks. (e) Sports socks. (f) Shoes
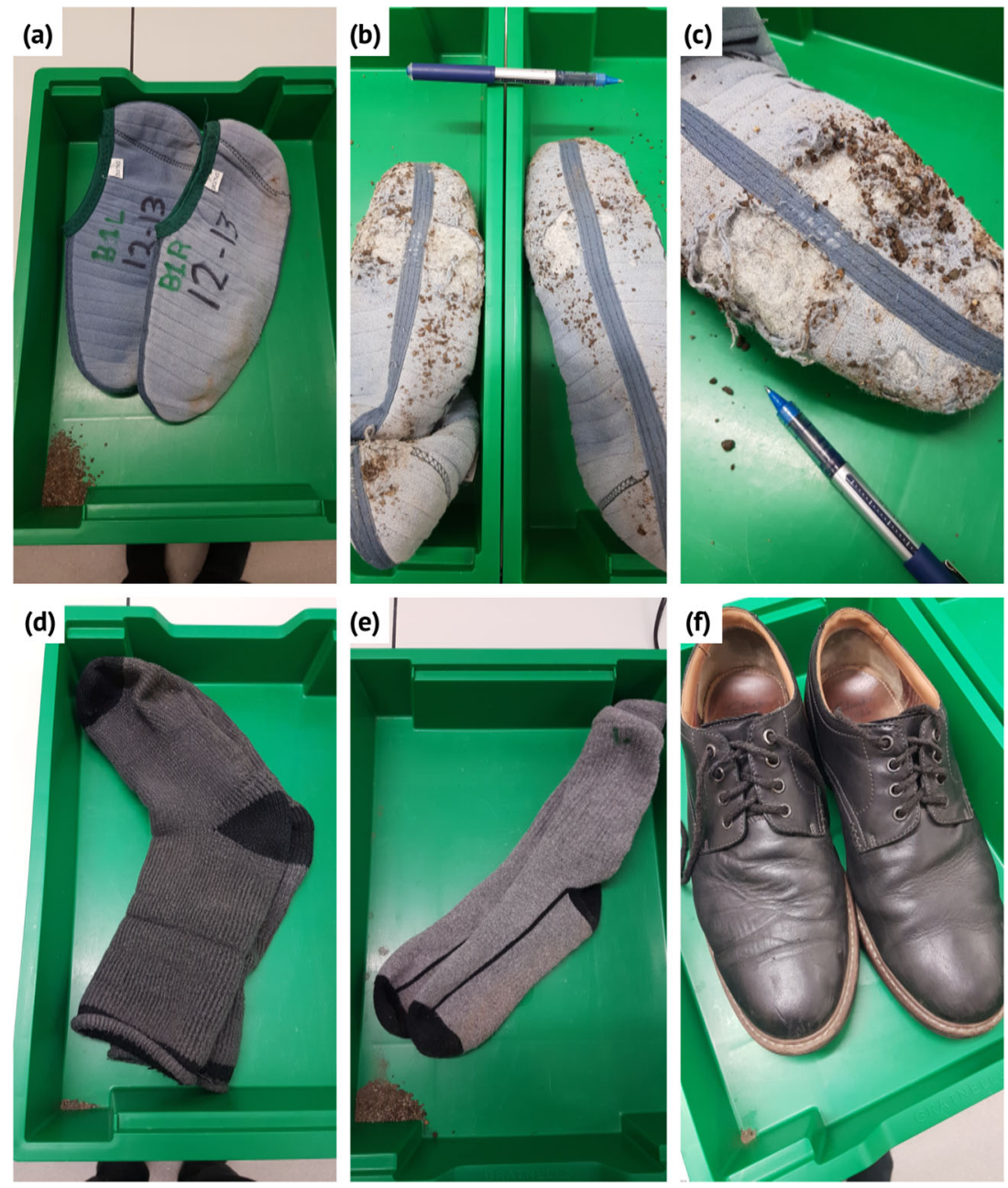

Such footwear was only used before the site was formally recognised for its scientific value and the need for protection.

\section{Results}

When tested with dry sediment, all footwear types were found to pick up on average between 0 and $0.2 \mathrm{~g}$ of sediment (Fig. 5). Visual analysis suggests that adherent dry sediment is mostly composed of dusty material, with no grains being coarser than very fine sand. While differences between the footwear types were observed, the amounts of dry adherent sediment measured were close to the analytical resolution of the balance, and the mean averages for all footwear types were within the 1 standard deviation range of the other footwear types. The differences in sediment weight between footwear types in dry conditions are therefore not considered to be statistically significant.
In contrast, significant differences in the mass of sediment adhered to footwear were observed when the experiment involved testing damp sediment (Fig. 6). The nearly new bama was found to be the worst performer, with on average $3.75 \mathrm{~g}$ of sediment adhering to each foot. This was followed by the old bama (3.47 g of adherent sediment per foot), the sports sock ( $2.78 \mathrm{~g}$ of adherent sediment per foot), the walking sock $(0.38 \mathrm{~g}$ of adherent sediment per foot), and the shoe $(0.18 \mathrm{~g}$ of adherent sediment per foot).

The initial mass of the sediment when wet was $3.1497 \mathrm{~kg}$, which decreased by $0.0939 \mathrm{~kg}$ when dried. This implies that the sediment used for the experiment held about $3 \%$ moisture content at the time of experimentation.

\section{Discussion}

During the process of securing the inscription of Mistaken Point as a UNESCO World Heritage Site, concern had been raised about the effects of foot traffic on the fossil surfaces. This concern is heightened by the recognition that inscription 
Fig. 5 Chart showing the mean average amount of dry sediment adhered to the sole of each footwear type. The range bars reflect one standard deviation about the mean value shown by the square marker

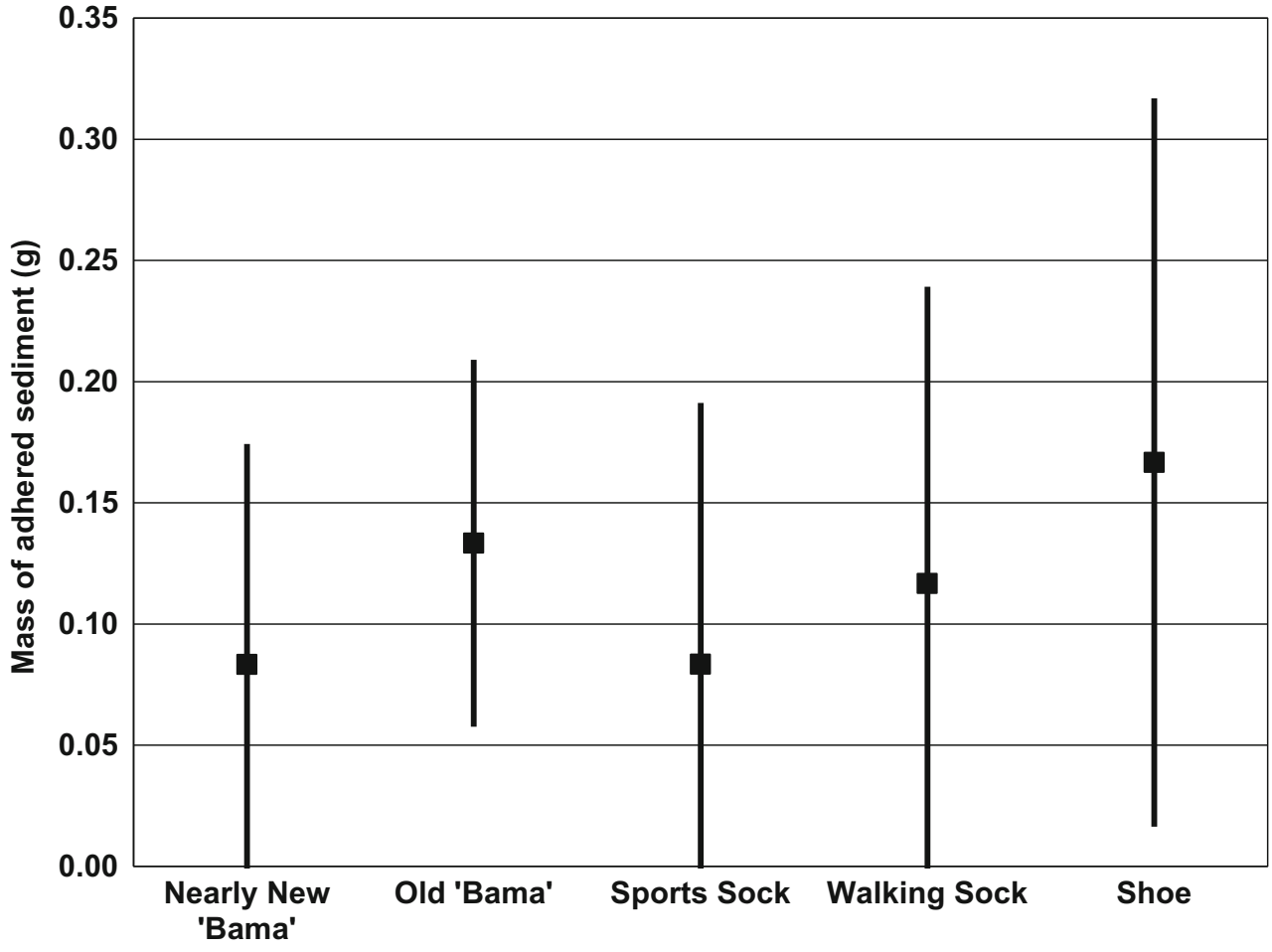

has led to a dramatic increase in the number of people taking the guided tour to the ' $D$ ' and ' $E$ ' Surfaces (MPER manager pers. comm.).

Since natural stone is a common flooring material, its abrasion has been well studied (e.g. Frick 1969) and is directly analogous to walking on a bedding surface such as the fossiliferous surfaces at Mistaken Point. In general terms, the abrasion of a stone surface (bedding plane) by moving objects (i.e. the soles of different footwear in our case study) can be divided into two different processes:

1. Two-body abrasion: where either the footwear has a rough lower surface or abrasive particles are tightly fixed to the footwear
Fig. 6 Chart showing the mean average amount of wet sediment adhered to the sole of each footwear type. The range bars reflect one standard deviation about the mean value shown by the circular marker

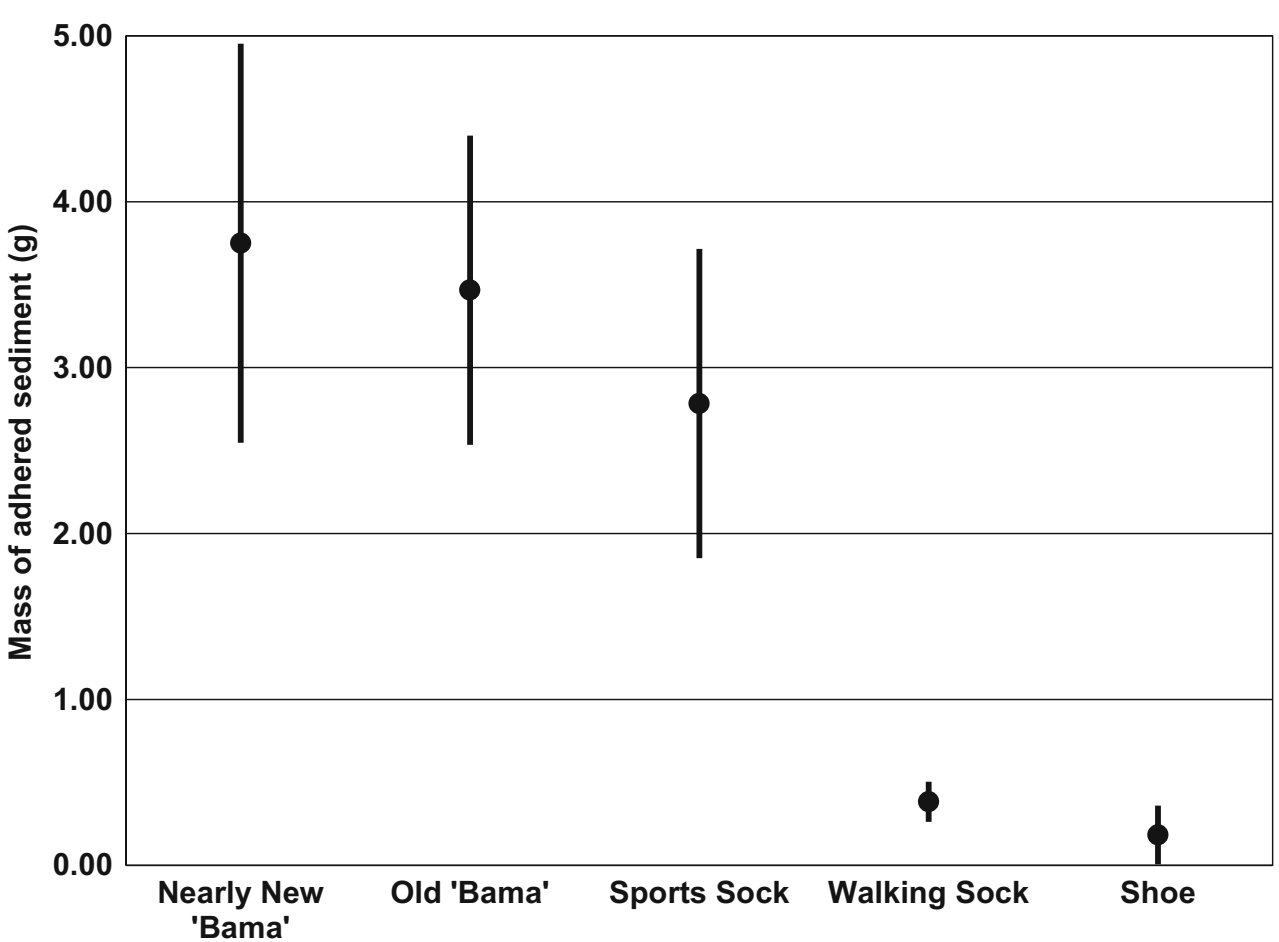


2. Three-body abrasion: where abrasive particles are loose and free to shift between the footwear and the bedding surface

In three-body abrasion, two surfaces slide past each other, interspersed by third bodies - usually particles that slide or roll during motion (Hutchings and Shipway 2017). The friction between the moving third bodies and the flooring surface causes a polishing effect, abrading the surface (Frick 1969). The main cause of wear on stone floors, and by analogy geological bedding surfaces, is from three-body abrasion (Y1lmaz et al. 2017).

While short-term events involving two-body abrasion can be highly destructive (e.g. when a stone is stuck in the tread of a shoe which then scratches a flooring surface), three-body abrasion is the dominant form of abrasion underfoot, as it occurs much more consistently and is less obvious to the walker.

If these principles of materials science are to be applied to conservation of fossil surfaces upon which people walk, one aim should be to reduce the amount of sediment caught between footwear and the fossil surface, thereby cutting the amount of three-body abrasion on the surface. Three possible means to ameliorate three-body abrasion at Mistaken Point are:

1. Reduce the amount of sediment on the surface before visitors arrive

2. Reduce the amount of sediment brought onto the surface by visitors

3. Reduce the ability of footwear to transport sediment when on the surface

If we accept three-body abrasion is the dominant wear process, and this is controlled by the availability of abrasive particles, aims 2 and 3 can be met by requiring footwear with minimal sediment adhesion to be worn before walking on the Mistaken Point surfaces.

While all the tested footwear types were found to transport a similar amount of dry sediment, significant differences were observed when the sediment was wet. This observation is of importance since during the period when tours were in operation in 2016, the nearby Cape Race weather station recorded a mean daily rainfall of $3.4 \mathrm{~mm}$, and some kind of precipitation was recorded on $40 \%$ of days.

While it was found that a shoe transports the least amount of wet sediment relative to the other footwear types, there is an enhanced risk that large abrasive clasts could lodge in the tread, causing the less-common, but highly damaging, twobody abrasion, potentially producing pock marks and scratches. Shoes with any sole capable of having sediment lodged in the tread are therefore ruled out as suitable footwear on protected geological surfaces.

The type of footwear that was most efficient at transporting sediment — and therefore most likely to cause abrasion — was the 'Bama Sokkets'. Old bamas were found to transport slightly less sediment than nearly new bamas when wet. This was counter to our expectations, since the extra texture at the frayed edges of the cloth in the old bamas (Fig. 4c) was thought to provide more capacity to carry sediment than the smoother new bamas. Detailed empirical observation of the soles of the 'Bama Sokkets' after the wet sediment tests revealed that, in areas where the outer layer of blue cotton cloth had been worn away, less sediment adhered to the sole (Fig. $4 \mathrm{~b}, \mathrm{c})$.

It is hypothesised herein that the reason for the difference in sediment adherence between the two types of 'Bama Sokkets', and between the other types of footwear, is due to the different proportions of hydrophobic and hydrophilic materials used in its construction. A review of the materials used in the tested footwear, their compositions, and their hydrophilic/hydrophobic properties is given in Table 1. In nearly new bamas, the blue outer lining of cotton provides a hydrophilic surface across all of the sole, onto which damp sediment can adhere. In the old bamas, months of use leads to the wearing-away of the cotton outer lining, mostly from around the ball of the foot, exposing the underlying hydrophobic layer of acrylic/polyester fleece. Empirical observations during the course of experimentation determined that damp sediment was much less likely to adhere to the acrylic/ polyester fleece inner than the cotton outer of the 'Bama Sokkets'.

The sports sock tested was composed predominantly of hydrophilic cotton, with some hydrophobic fibres, and was
Table. 1 Table showing the composition of different materials comprising the footwear types tested and their hydrophobic or hydrophilic properties

\begin{tabular}{lll}
\hline Name & Composition & $\begin{array}{l}\text { Hydrophobic/ } \\
\text { Hydrophilic }\end{array}$ \\
\hline Acrylic & Polyacrylonitrile & Hydrophobic \\
Cotton & Natural fibre from Gossypium plant & Hydrophilic \\
Polyester & Polyethylene terephthalate & Hydrophobic \\
Nylon/polyamide & Synthetic polymer based on polyamides & Hydrophilic \\
Elastane & Polyether-polyurea copolymer & Hydrophobic \\
Rubber & Polymers of natural isoprene & Hydrophobic \\
\hline
\end{tabular}


found to transport significantly more sediment in wet conditions than when dry. In contrast, the walking sock testeddespite its coarser weave relative to the sports sock-was found to transport less sediment. While the amount of wet sediment transported by the walking sock was more than during experiments involving dry sediment, this increase was much smaller than in either the 'Bama Sokkets' or the sports sock and is likely explained by the lack of hydrophilic fibres in the walking sock.

From the experimental evidence presented herein, it is determined that the major control on sediment adherence to footwear is the material that it has been constructed from. Footwear made from hydrophobic fibres is less likely to transport damp sediment and so will reduce three-body abrasion on rock surfaces, when compared to hydrophilic alternatives. These results have led to a change of policy at MPER, and from 2019, the Government of Newfoundland and Labrador will be discontinuing the use of 'Bama Sokkets' and will replace them with a hydrophobic alternative.

\section{Conclusion}

Since 2008, visitors to the most spectacular fossil surfaces within the Mistaken Point Ecological Reserve have had to wear 'Bama Sokkets' when walking on these internationally significant geosites. This footwear type is made of acrylic/ polyester fleece, covered in an outer layer of cotton textile. Evidence presented herein suggests this cotton layer is particularly prone to transporting damp sediment, which is significant as the ability of a footwear type to transport sediment on its sole is a major control on the amount of abrasion that will occur between the sole and an underlying fossil surface.

While the decision to begin using 'Bama Sokkets' was well intentioned, and in keeping with the best practice at the time, these new data show that a footwear type constructed of hydrophobic fibres would have produced better geoconservation outcomes by decreasing instances of three-body abrasion on the fossil surfaces. The removal of footwear remains an essential management protocol at the site, and there is anecdotal evidence to suggest that making visitors wear a particular piece of footwear increases awareness of how actions may adversely affect the site. Further research is required to understand the natural erosional processes at the site and to quantify the possible abrasion caused by foot traffic.

Many important geosites require researchers and geotourists to walk across rock surfaces to study and observe geoheritage. The results of this study are therefore pertinent not only to the geoconservation of Ediacaran fossil sites in Newfoundland, but also to other bedding planes hosted geoheritage worldwide, such as dinosaur trackways and certain fossil lagerstätte.
Acknowledgements Permits for research within the Mistaken Point Ecological Reserve are required and available from the Department of Fisheries and Land Resources. The thoughtful comments of two reviewers greatly assisted in improving this manuscript. The continued assistance of the communities of the Southern Shore, Newfoundland, and the staff at MPER is gratefully acknowledged, as is the support of the Legendary Coasts Destination Management Organisation.

Funding Information This research was supported by funding from MITACS and the Department of Fisheries and Land Resources, Government of Newfoundland and Labrador, as well as NSERC DG funding to Prof. Duncan McIlroy.

Open Access This article is distributed under the terms of the Creative Commons Attribution 4.0 International License (http:// creativecommons.org/licenses/by/4.0/), which permits unrestricted use, distribution, and reproduction in any medium, provided you give appropriate credit to the original author(s) and the source, provide a link to the Creative Commons license, and indicate if changes were made.

\section{References}

Bamforth EL, Narbonne GM (2009) New Ediacaran rangeomorphs from Mistaken Point, Newfoundland, Canada. J Paleontol 83:897-913

Benus AP (1988) Sedimentological context of a deep-water Ediacaran fauna (Mistaken Point, Avalon Zone, eastern Newfoundland) Bull NY St Mus 463:8-9

Boag TH, Darroch SAF, Laflamme M (2016) Ediacaran distributions in space and time: testing assemblage concepts of earliest macroscopic body fossils. Paleobiology 42:574-594. https://doi.org/10.1017/ pab.2016.20

Brasier MD, Antcliffe JB (2009) Evolutionary relationships within the Avalonian Ediacara biota: new insights from laser analysis. J Geol Soc 166:363-384

Brasier MD, Antcliffe JB, Liu AG (2012) The architecture of Ediacaran fronds. Palaeontology 55:1105-1124. https://doi.org/10.1111/j. 1475-4983.2012.01164.x

Clapham ME, Narbonne GM, Gehling JG (2003) Paleoecology of the oldest known animal communities: Ediacaran assemblages at Mistaken Point, Newfoundland. Paleobiology 29:527-544. https:// doi.org/10.1666/0094-8373(2003)029<0527:POTOKA>2.0.CO;2

Darroch SAF, Laflamme M, Clapham ME (2013) Population structure of the oldest known macroscopic communities from Mistaken Point, Newfoundland. Paleobiology 39:591-608. https://doi.org/10.1666/ 12051

Darroch SAF, Sperling EA, Boag TH, Racicot RA, Mason SJ, Morgan AS, Tweedt S, Myrow P, Johnston DT, Erwin DH, Laflamme M (2015) Biotic replacement and mass extinction of the Ediacara biota. Proc R Soc B 282:20151003. https://doi.org/10.1098/rspb.2015. 1003

Dufour SC, McIlroy D (2017) Ediacaran pre-placozoan diploblasts in the Avalonian biota: the role of chemosynthesis in the evolution of early animal life. Geol Soc Lond Spec Publ 448:211-219. https://doi.org/ $10.1144 / \mathrm{SP} 448.5$

Fedonkin MA, Simonetti A, Ivantsov AY (2007) New data on Kimberella, the Vendian mollusc-like organism (White Sea region, Russia): palaeoecological and evolutionary implications. In: The rise and fall of the Ediacaran biota. Special Publication, London, Geological Society, pp 157-179

Flude LI, Narbonne GM (2008) Taphonomy and ontogeny of a multibranched Ediacaran fossil: Bradgatia from the Avalon Peninsula of Newfoundland. Can J Earth Sci 45:1095-1109 
Frick OFV (1969) Studies of wear on flooring materials. Wear 14:119131. https://doi.org/10.1016/0043-1648(69)90342-1

Gehling JG, Narbonne GM (2007) Spindle-shaped Ediacara fossils from the Mistaken Point assemblage, Avalon Zone, Newfoundland. Can J Earth Sci 44:367-387. https://doi.org/10.1139/E07-003

Hutchings I, Shipway P (2017) 6 - Wear by hard particles. In: Hutchings I, Shipway P (eds) Tribology, Second edn. Butterworth-Heinemann, pp 165-236

Laflamme M, Narbonne GM, Anderson MM (2004) Morphometric analysis of the ediacaran frond Charniodiscus from the mistaken point formation, Newfoundland. J Paleontol 78:827-837

Liu AG, Matthews JJ (2017) Great Canadian Lagerstätten 6. Mistaken Point Ecological Reserve, Southeast Newfoundland. Geosci Can 44: 63-76. https://doi.org/10.12789/geocanj.2017.44.117

Liu AG, Mcilroy D, Antcliffe JB, Brasier MD (2011) Effaced preservation in the Ediacara biota and its implications for the early macrofossil record. Palaeontology 54:607-630. https://doi.org/10.1111/j. 1475-4983.2010.01024.x

Liu AG, Kenchington CG, Mitchell EG (2015) Remarkable insights into the paleoecology of the Avalonian Ediacaran macrobiota. Gondwana Res 27:1355-1380. https://doi.org/10.1016/j.gr.2014. 11.002

Liu AG, Matthews JJ, McIlroy D (2016) The Beothukis/Culmofrons problem and its bearing on Ediacaran macrofossil taxonomy: evidence from an exceptional new fossil locality. Palaeontology 59:4558. https://doi.org/10.1111/pala.12206
Matthews JJ, Liu AG, McIlroy D (2017) Post-fossilization processes and their implications for understanding Ediacaran macrofossil assemblages. Geol Soc Lond Spec Publ 448:SP448.20. https://doi.org/10. 1144/SP448.20

Mitchell EG, Kenchington CG, Liu AG, Matthews JJ, Butterfield NJ (2015) Reconstructing the reproductive mode of an Ediacaran macro-organism. Nature 524:343-346. https://doi.org/10.1038/ nature 14646

Narbonne GM (2004) Modular construction of early ediacaran complex life forms. Science 305:1141-1144. https://doi.org/10.1126/science. 1099727

Narbonne GM (2005) The Ediacara biota: neoproterozoic origin of animals and their ecosystems. Annu Rev Earth Planet Sci 33:421-442. https://doi.org/10.1146/annurev.earth.33.092203.122519

Pu JP, Bowring SA, Ramezani J, Myrow P, Raub TD, Landing E, Mills A, Hodgin E, Macdonald FA (2016) Dodging snowballs: geochronology of the Gaskiers glaciation and the first appearance of the Ediacaran biota. Geology 44:955-958. https://doi.org/10.1130/ G38284.1

Seilacher A (1992) Vendobionta and Psammocorallia - lost constructions of Precambrian evolution. J Geol Soc 149:607-613

Y1lmaz NG, Goktan RM, Onargan T (2017) Correlative relations between three-body abrasion wear resistance and petrographic properties of selected granites used as floor coverings. Wear 372:197-207. https://doi.org/10.1016/j.wear.2016.12.024 